\title{
Correction to: Beyond Burnout: Responding to the COVID-19 Pandemic Challenges to Self-care
}

\author{
Richard F. Mollica ${ }^{1}$. Dinali B. Fernando ${ }^{2,3,4}$ - Eugene F. Augusterfer ${ }^{5}$
}

Published online: 27 May 2021

(C) Springer Science+Business Media, LLC, part of Springer Nature 2021

\section{Correction to: Current Psychiatry Reports (2021) 23: 21.} https://doi.org/10.1007/s11920-021-01230-2

After publication, a quote was removed from this article and a reference was corrected because they were inaccurate.

Publisher's Note Springer Nature remains neutral with regard to jurisdictional claims in published maps and institutional affiliations.

The online version of the original article can be found at https://doi.org/ 10.1007/s11920-021-01230-2

Eugene F. Augusterfer

efa@gmhnet.com

Richard F. Mollica

rmollica@partners.org

Dinali B. Fernando

dinali.fernando@mssm.edu

1 Harvard Medical School, Massachusetts General Hospital,

Boston, MA, USA

2 Department of Emergency Medicine, Icahn School of Medicine at Mount Sinai, New York, NY, USA

3 Department of Emergency Medicine, Elmhurst Hospital, Elmhurst, NY, USA

4 Libertas Center for Human Rights, Elmhurst Hospital, Elmhurst, NY, USA

5 Harvard Global Mental Health: Trauma and Recovery Program, Harvard Medical School, Boston, MA, USA 